\title{
Structure-functional changes in eNAMPT at high concentrations mediate mouse and human beta cell dysfunction in type 2 diabetes
}

\author{
Sophie R. Sayers ${ }^{1} \cdot$ Rebecca L. Beavil $^{2} \cdot$ Nicholas H. F. Fine $^{3,4,5} \cdot$ Guo C. Huang $^{1}$ • Pratik Choudhary ${ }^{1}$. \\ Kamila J. Pacholarz ${ }^{6}$. Perdita E. Barran ${ }^{6}$. Sam Butterworth ${ }^{7}$. Charlotte E. Mills ${ }^{8,9}$. J. Kennedy Cruickshank ${ }^{8}$. \\ Marta P. Silvestre ${ }^{10}$. Sally D. Poppitt ${ }^{10}$. Anne-Thea McGill ${ }^{10,11}$. Gareth G. Lavery ${ }^{3,4,5}$. David J. Hodson ${ }^{3,4,5}$. \\ Paul W. Caton ${ }^{1,8}$
}

Received: 21 February 2019 / Accepted: 11 September 2019/Published online: 15 November 2019

(C) The Author(s) 2019

\begin{abstract}
Aims/hypothesis Progressive decline in functional beta cell mass is central to the development of type 2 diabetes. Elevated serum levels of extracellular nicotinamide phosphoribosyltransferase (eNAMPT) are associated with beta cell failure in type 2 diabetes and eNAMPT immuno-neutralisation improves glucose tolerance in mouse models of diabetes. Despite this, the effects of eNAMPT on functional beta cell mass are poorly elucidated, with some studies having separately reported beta cell-protective effects of eNAMPT. eNAMPT exists in structurally and functionally distinct monomeric and dimeric forms. Dimerisation is essential for the NAD-biosynthetic capacity of NAMPT. Monomeric eNAMPT does not possess NAD-biosynthetic capacity and may exert distinct NAD-independent effects. This study aimed to fully characterise the structure-functional effects of eNAMPT on pancreatic beta cell functional mass and to relate these to beta cell failure in type 2 diabetes.

Methods CD-1 mice and serum from obese humans who were without diabetes, with impaired fasting glucose (IFG) or with type 2 diabetes (from the Body Fat, Surgery and Hormone [BodyFatS\&H] study) or with or at risk of developing type 2 diabetes (from the VaSera trial) were used in this study. We generated recombinant wild-type and monomeric eNAMPT to explore the effects of eNAMPT on functional beta cell mass in isolated mouse and human islets. Beta cell function was determined by static and dynamic insulin secretion and intracellular calcium microfluorimetry. NAD-biosynthetic capacity of eNAMPT was assessed by colorimetric and fluorescent assays and by native mass spectrometry. Islet cell number was determined by immunohistochemical staining for insulin, glucagon and somatostatin, with islet apoptosis determined by caspase 3/7 activity. Markers of inflammation and beta cell identity were determined by quantitative reverse transcription PCR. Total, monomeric and dimeric eNAMPT and
\end{abstract}

Electronic supplementary material The online version of this article (https://doi.org/10.1007/s00125-019-05029-y) contains peer-reviewed but unedited supplementary material, which is available to authorised users.

Paul W. Caton

paul.w.caton@kcl.ac.uk

1 Diabetes Research Group, Department of Diabetes, School of Life Course Sciences, King's College London, Hodgkin Building, Guy's Campus, London SE1 1UL, UK

2 Protein Production Facility, Randall Centre for Cell and Molecular Biophysics, King's College London, London, UK

3 Institute of Metabolism and Systems Research (IMSR), University of Birmingham, Birmingham, UK

4 Centre of Membrane Proteins and Receptors (COMPARE), University of Birmingham, Birmingham, UK

5 Centre for Endocrinology, Diabetes and Metabolism, Birmingham Health Partners, Birmingham, UK
6 Michael Barber Centre for Collaborative Mass Spectrometry, School of Chemistry, Manchester Institute of Biotechnology, Manchester, UK

7 Division of Pharmacy and Optometry, Faculty of Biology, Medicine and Health, University of Manchester, Manchester, UK

8 Department of Nutritional Sciences, School of Life Course Sciences, King's College London, London, UK

9 Nutrition Research Group, University of Reading, Reading, UK

10 Human Nutrition Unit, School of Biological Sciences, University of Auckland, Auckland, New Zealand

11 School of Health \& Human Sciences, Southern Cross University, Lismore, NSW, Australia 


\section{Research in context}

\section{What is already known about this subject?}

- Serum concentrations of extracellular nicotinamide phosphoribosyltransferase (eNAMPT) are elevated in type 2 diabetes

- However, previous studies have shown both deleterious and protective effects of eNAMPT on the pancreatic beta cell

- $\quad$ eNAMPT exists in monomer and dimer forms. Our previous studies have suggested that structure-functional relationships may mediate the diverse reported effects of eNAMPT

What is the key question?

- What are the selective roles of monomeric and dimeric eNAMPT on pancreatic beta cell function and mass?

\section{What are the new findings?}

- In humans, serum eNAMPT concentrations increase with progression from normoglycaemia to type 2 diabetes. However, these increases are not associated with an increase in the NAD-biosynthetic activity of eNAMPT. Instead, they are characterised by a marked increase in non-NAD-biosynthetic monomeric eNAMPT and a relative decline in dimeric (NAD-synthesising) eNAMPT

- At low, physiological levels, eNAMPT is present solely in dimeric form and promotes beta cell function through NAD-biosynthetic effects in mouse and human islets

- In humans, as levels of eNAMPT rise to pathophysiological levels $(\sim 5 \mathrm{ng} / \mathrm{ml})$, as in type 2 diabetes, eNAMPT adopts monomeric form and induces beta cell failure through NAD-independent effects. In mouse and human islets, monomeric eNAMPT drives beta cell failure, in part through promoting islet inflammation via NAD-independent mechanisms

\section{How might this impact on clinical practice in the foreseeable future?}

- Developing compounds to selectively target monomeric eNAMPT or stabilise eNAMPT in its dimeric form could improve functional beta cell mass and may be used to treat type 2 diabetes, through both elevation of islet NAD levels and by blocking the proinflammatory NAD-independent effects of eNAMPT monomer

nicotinamide mononucleotide (NMN) were evaluated by ELISA, western blot and fluorometric assay using serum from nondiabetic, glucose intolerant and type 2 diabetic individuals.

Results eNAMPT exerts bimodal and concentration- and structure-functional-dependent effects on beta cell functional mass. At low physiological concentrations $(\sim 1 \mathrm{ng} / \mathrm{ml})$, as seen in serum from humans without diabetes, eNAMPT enhances beta cell function through NAD-dependent mechanisms, consistent with eNAMPT being present as a dimer. However, as eNAMPT concentrations rise to $\sim 5 \mathrm{ng} / \mathrm{ml}$, as in type 2 diabetes, eNAMPT begins to adopt a monomeric form and mediates beta cell dysfunction, reduced beta cell identity and number, increased alpha cell number and increased apoptosis, through NADindependent proinflammatory mechanisms.

Conclusions/interpretation We have characterised a novel mechanism of beta cell dysfunction in type 2 diabetes. At low physiological levels, eNAMPT exists in dimer form and maintains beta cell function and identity through NAD-dependent mechanisms. However, as eNAMPT levels rise, as in type 2 diabetes, structure-functional changes occur resulting in marked elevation of monomeric eNAMPT, which induces a diabetic phenotype in pancreatic islets. Strategies to selectively target monomeric eNAMPT could represent promising therapeutic strategies for the treatment of type 2 diabetes.

Keywords Beta cell $\cdot$ eNAMPT Extracellular nicotinamide phosphoribosyltransferase $\cdot$ Inflammation $\cdot$ Insulin secretion · NAD - Type 2 diabetes

\section{Abbreviations}

AMP-CP

eNAMPT
Adenosine 5 '- $(\alpha, \beta$-methylene $)$ diphosphate

Extracellular nicotinamide

phosphoribosyltransferase
eNAMPT-WT Recombinant wild-type extracellular nicotinamide phosphoribosyltransferase

FPG Fasting plasma glucose

GSIS Glucose-stimulated insulin secretion 


\begin{tabular}{|c|c|}
\hline IFG & Impaired fasting glucose \\
\hline iNAMPT & $\begin{array}{l}\text { Intracellular nicotinamide } \\
\text { phosphoribosyltransferase }\end{array}$ \\
\hline JNK & c-Jun N-terminal kinase \\
\hline MAPK & Mitogen-activated protein kinase \\
\hline NAMPT & Nicotinamide phosphoribosyltransferase \\
\hline NMN & Nicotinamide mononucleotide \\
\hline STAT3 & $\begin{array}{l}\text { Signal transducer and activator of } \\
\text { transcription } 3\end{array}$ \\
\hline WT & Wild-type \\
\hline
\end{tabular}

\section{Introduction}

Elucidating the underlying mechanisms responsible for progressive decline in functional beta cell mass is essential for the design of novel treatments for type 2 diabetes [1]. The protein nicotinamide phosphoribosyltransferase (NAMPT) exists in intracellular (iNAMPT) and extracellular (eNAMPT) forms. eNAMPT (also known as visfatin/pre-B cell enhancing factor [PBEF]) is a circulating protein with several reported functions [2-4]. Similar to iNAMPT, eNAMPT may exert NAD-biosynthetic effects, whereby eNAMPT catalyses the conversion of nicotinamide to nicotinamide mononucleotide (NMN) in serum $[5,6]$. NMN may subsequently be transported into the cell (directly or via conversion into nicotinamide riboside), where it is converted into NAD by nicotinamide mononucleotide adenylyltransferases (NMNATs) 1-3. However, this mechanism has been disputed and NAD-independent functions, including eNAMPT-mediated proinflammatory effects, are also reported [4, 7-9].

Serum eNAMPT levels are elevated in type 2 diabetes, in association with declining beta cell function. Our in vivo studies indicate that eNAMPT may mediate type 2 diabetes pathophysiology [10-12]. Contrasting studies report that eNAMPT and its reaction product NMN exert beta cell-protective effects by boosting cellular NAD levels [6, 13-19].

A key, but frequently overlooked factor governing eNAMPT function is the presence of structurally and functionally distinct monomeric $(\sim 52 \mathrm{KDa})$ and dimeric $(\sim 104 \mathrm{KDa})$ eNAMPT. Dimerisation is essential for NAD-biosynthetic capacity of eNAMPT $[6,20]$ and the eNAMPT dimer predominates in normal physiology $[12,15]$. The eNAMPT monomer does not possess NAD-biosynthetic capacity and may mediate NADindependent proinflammatory effects. Our studies suggested a specific pathophysiological role for monomeric eNAMPT in mouse models of diabetes [12]. We hypothesised that, in type 2 diabetes, eNAMPT monomer is selectively elevated, which exerts NAD-independent proinflammatory effects, and that this, combined with the loss of eNAMPT's NAD-biosynthetic capacity, plays a key role in disease pathophysiology.

However, whether eNAMPT monomer is elevated in type 2 diabetes and to what extent the structurally distinct forms of
eNAMPT directly affect the pancreatic beta cell are unknown. Previous studies, including our own, have examined NADboosting effects of NMN on beta cell function [6,13,14], or have examined supraphysiological concentrations or acute effects of eNAMPT [21, 22], neither of which accurately mimic in vivo (patho)physiology. Of perhaps greater importance, the selective effects of monomeric and dimeric eNAMPT on beta cell health have not been examined.

We used isolated mouse and human islets, and serum from humans with type 2 diabetes, to specifically characterise the effects of monomeric and dimeric eNAMPT on pancreatic beta cell functional mass.

\section{Methods}

Animals Eight-week-old male CD-1 mice (28-33 g; Envigo, Blackthorn, UK) were housed in $12 \mathrm{~h}$ light/dark cycle, temperature-controlled conditions with ad libitum access to standard mouse chow (Envigo) and water. Procedures were performed in accordance with UK Home Office regulations (Animal Scientific Procedures Act, 1986).

Human samples Human serum was obtained from obese individuals without diabetes, (BMI $>30 \mathrm{~kg} / \mathrm{m}^{2}$; fasting plasma glucose [FPG] $<5.6 \mathrm{mmol} / \mathrm{l} ; n=13$ individuals), with impaired fasting glucose (IFG; BMI $>30 \mathrm{~kg} / \mathrm{m}^{2}$; FPG 5.6-6.9 mmol/ $/ ; n=$ 15 individuals)) or with type 2 diabetes (BMI $>30 \mathrm{~kg} / \mathrm{m}^{2} ; \mathrm{FPG}$ $>7.0 \mathrm{mmol} / \mathrm{l} ; n=27$ individuals), as part of the Body Fat, Surgery and Hormone (BodyFatS\&H) study (University of Auckland, Auckland, New Zealand) and from obese individuals with or at risk of developing type 2 diabetes as part of the VaSera trial (St Thomas' Hospital, London) [23, 24]. Study participants gave informed consent. Investigations were approved by the Northern Regional Ethics Committee (NREC), Auckland, New Zealand (BodyFatS\&H) and the National Research Ethics Service (NRES) Committee, London Central (VaSera). See electronic supplementary material (ESM) Methods for further details.

Native mass spectrometry Native mass spectrometry was conducted using the Synapt G2S high definition mass spectrometer (HDMS; Waters, Manchester, UK) (see ESM Methods).

eNAMPT protein generation Recombinant wild-type (WT) eNAMPT (eNAMPT-WT) and mutant $\mathrm{SS}^{199} / 200 \mathrm{DD}$ (eNAMPT monomer) were produced in Escherichia coli. See ESM Methods for details.

Pancreatic islet isolation Mouse islets were isolated between 9:00 and 10:00 hours [25]. Human islets were isolated from heart-beating non-diabetic donors, with ethical approval, at the King's College Hospital Human Islet Isolation Unit (London, UK) [25] (see ESM Human Islets Checklist for further details). 
All isolated islets were incubated overnight $\left(37^{\circ} \mathrm{C}, 5 \% \mathrm{CO}_{2}\right)$ prior to treatments (ESM Methods). RPMI media was used for all incubations. Islets were size-matched prior to treatments. Mouse and human islets were treated with eNAMPT (WT or monomer; $0.1-5 \mathrm{ng} / \mathrm{ml})$ or NMN (100 $\mu \mathrm{mol} / \mathrm{l})$ for 24,48 or $72 \mathrm{~h}$. For inflammatory pathway inhibition, mouse islets were incubated with $1 \mathrm{ng} / \mathrm{ml}$ eNAMPT monomer or $5 \mathrm{ng} / \mathrm{ml}$ eNAMPT-WT, in combination with inhibitors of signal transducer and activator of transcription 3 (STAT3; using NCS74859; $50 \mu \mathrm{mol} / \mathrm{l}$ ), P38mitogen-activated protein kinase (MAPK; using SB203580; $1 \mu \mathrm{mol} / \mathrm{l}$ ), NF-кB (using BAY 11-7082; $1 \mu \mathrm{mol} / \mathrm{l}$ ) or c-Jun Nterminal kinase (JNK; using SP600125; $50 \mu \mathrm{mol} / \mathrm{l}$ ), (Tocris Biosciences, Abingdon, UK). For CD73 inhibition, mouse islets were incubated with $0.5-5 \mathrm{ng} / \mathrm{ml}$ eNAMPT-WT for $48 \mathrm{~h}$ in combination with adenosine $5^{\prime}-(\alpha, \beta$-methylene $)$ diphosphate (AMP-CP; $1 \mu \mathrm{mol} / \mathrm{l}$; Sigma-Aldrich, Poole, UK)

\section{Static and dynamic glucose-stimulated insulin secretion} Static or dynamic insulin secretion was assessed in response to $2 \mathrm{mmol} / 1$ or $20 \mathrm{mmol} / 1$ glucose exposure, as previously described [25]. Secreted insulin was measured by in-house ${ }^{125}$ I radioimmunoassay [26] (see ESM Methods).

Endotoxin measurement Endotoxin concentrations were measured in recombinant eNAMPT preparations using the Pierce LAL Chromogenic Endotoxin Quantitation Kit (ThermoFisher Scientific, Altrincham, UK).

In vitro islet immunostaining Mouse islets were pelleted and fixed in $4 \%$ (vol./vol.) buffered formalin. Sections $(5 \mu \mathrm{mol} / \mathrm{l})$ were incubated with anti-guinea pig insulin (Dako, Stockport, UK; catalogue no. A0564), anti-rabbit glucagon (Abcam, Cambridge, UK; ab92517) or anti-rat somatostatin (Abcam; ab30788) (1:100 for all; K) and DAPI (ThermoFisher). Secondary antibodies used were AlexaFluor 488-labelled donkey anti-rat (712-545-1250), AlexaFluor 594-labelled donkey anti-guinea pig (06-585-148) and AlexaFluor 488labelled donkey anti-rabbit (711-545-152) (1:200 for all; Jackson ImmunoResearch, Cambridge UK). Sections were mounted on glass slides and captured on a Nikon TE2000 fluorescent microscope (Nikon Instruments, Melville, NY, USA) and quantified using ImageJ (https://imagej.nih.gov/ij/ download.html; accessed December 2017-June 2018).

Islet apoptosis Mouse islets were treated with eNAMPT with or without cytokine cocktail $(0.05 \mathrm{U} / \mu \mathrm{IL}-1 \beta, 1 \mathrm{U} / \mu \mathrm{l}$ TNF- $\alpha$ and $1 \mathrm{U} / \mu \mathrm{IFN} \gamma ; 48 \mathrm{~h})$. Apoptosis was determined by the CaspaseGlo 3/7 luminescent assay (Promega, Southampton, UK).

Quantitative reverse transcription PCR Gene expression was determined by SYBR Green quantitative reverse transcription PCR using $\Delta \Delta \mathrm{C}_{\mathrm{t}}$ methodology and normalised against glyceraldehyde 3-phosphate dehydrogenase (GAPDH)
(QuantiTect; Qiagen, Manchester, UK). See ESM Methods and ESM Table 1.

Intracellular calcium Whole mouse islets, incubated in HEPES bicarbonate buffer (containing 2-20 mmol/1 glucose), were loaded with Fura-2 AM and imaged using a Nikon Ti-E microscope equipped with FuraLEDs (Cairn Research, Faversham, UK) (excitation, 340/385 nm; emission, 470$550 \mathrm{~nm})$

MIN6 cell culture MIN6 cells (mycoplasma free; obtained from J. I. Miyazaki, Osaka University, Osaka, Japan [27, 28]) were cultured at $37^{\circ} \mathrm{C}$ in DMEM (25 mmol/l glucose; $2 \mathrm{mmol} / \mathrm{l}$ glutamine, 10\% FBS (vol./vol.), $100 \mathrm{U} / \mathrm{ml}$ penicillin, $100 \mu \mathrm{g} / \mathrm{ml}$ streptomycin) and treated with eNAMPT (1$5 \mathrm{ng} / \mathrm{ml} \mathrm{WT}$; $1 \mathrm{ng} / \mathrm{ml}$ monomer) or NMN (100 $\mu \mathrm{mol} / \mathrm{l})$ (48 h; Sigma-Aldrich), prior to NAD and NMN measurements.

eNAMPT, NAD and NMN measurements Total serum eNAMPT was measured by ELISA (Adipogen, Seoul, South Korea). MIN6 intracellular NAD and NMN levels were measured by an NAD/NADH Quantification Kit, (SigmaAldrich) and an in-house fluorometric assay, respectively [29, 30] (see ESM Methods).

eNAMPT Immunoblotting Serum eNAMPT monomer and dimer were measured by immunoblotting, under nonreducing conditions, as previously described [31]. To ensure equivalent loading of each lane, serum protein was normalised to $10 \mu \mathrm{g}$ and an equal volume $(30 \mu \mathrm{l})$ was added to each well (see ESM Methods).

Data analysis Data are expressed as mean \pm SEM. Significance was tested using one- or two-way ANOVA with Tukey's or Sidak's post hoc test, using GraphPad PRISM 7 software (San Diego, CA, USA). Experimenters were not blind to group assignment and outcome assessment.

\section{Results}

Serum eNAMPT monomer concentrations are elevated in type 2 diabetes and are positively correlated with increased $\mathrm{HbA}_{1 c}$ We first demonstrated that serum eNAMPT concentrations increased with progression of type 2 diabetes (Fig. 1a): in obese non-diabetic individuals, serum eNAMPT concentrations were $1.7 \pm 0.4 \mathrm{ng} / \mathrm{ml}$, rising to $3.4 \pm 0.7 \mathrm{ng} / \mathrm{ml}$ in individuals with IFG and $4.6 \pm 0.6 \mathrm{ng} / \mathrm{ml}$ in type 2 diabetes $(p<$ 0.05 vs non-diabetic for both IFG and type 2 diabetes). These concentrations are similar to those observed in previous studies [32-34]. Increasing eNAMPT concentrations strongly correlated $\left(r^{2}=0.3787 ; p<0.01\right)$ with increasing $\mathrm{HbA}_{1 \mathrm{c}}$ $(\mathrm{mmol} / \mathrm{mol})$, indicating a role of eNAMPT in mediating poor 

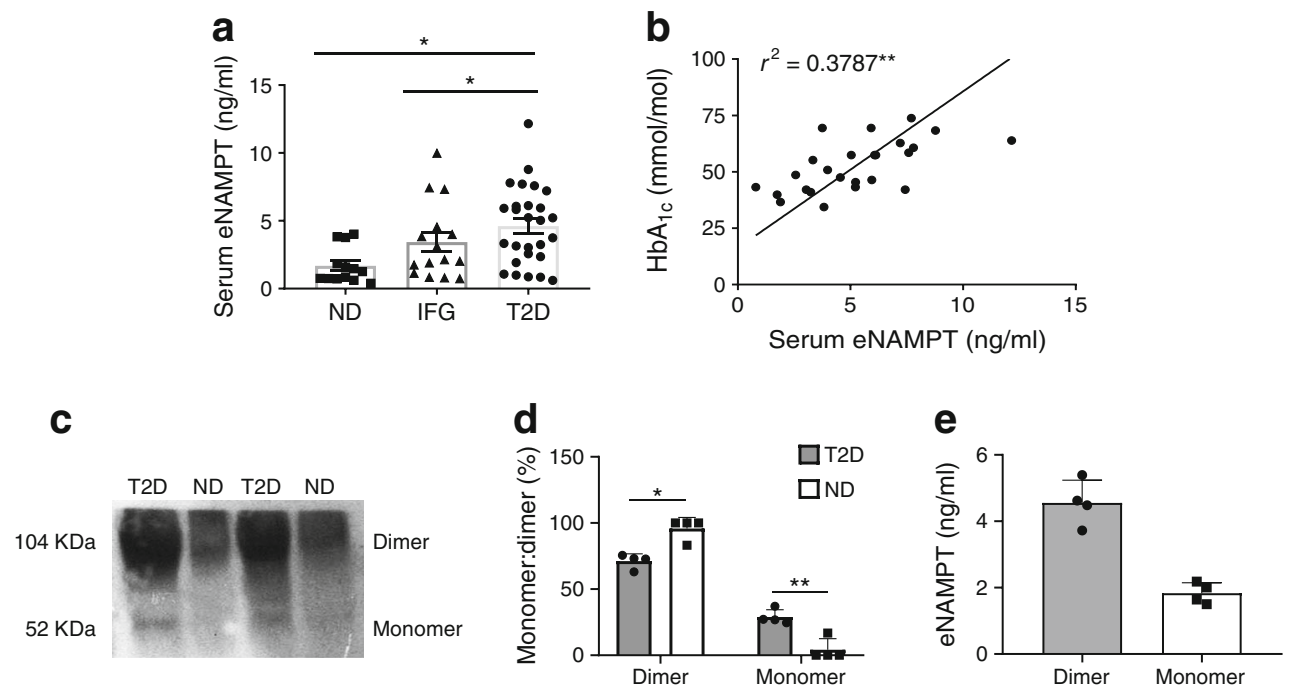

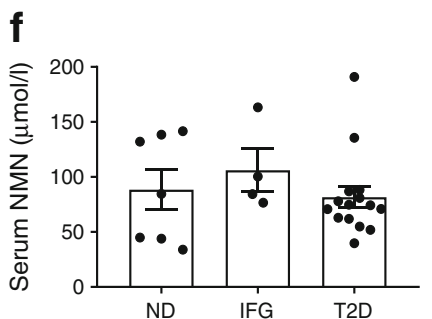

Fig. 1 Serum eNAMPT levels are increased in type 2 diabetes and are associated with increased $\mathrm{HbA}_{1 \mathrm{c}}$. Serum was collected from obese individuals without diabetes (non-diabetic [ND]), with IFG and with type 2 diabetes (T2D), and eNAMPT was measured by ELISA or immunoblot. (a) Serum eNAMPT (data generated from BodyFatS\&H and VaSera trial samples); (b) Serum eNAMPT vs $\mathrm{HbA}_{1 \mathrm{c}}$ (data generated from VaSera trial only). (c-e) Western blot of serum eNAMPT monomer and dimer (c) and quantification of percentage ratio of eNAMPT monomer and dimer in

glycaemic control (Fig. 1b). Next, we specifically measured serum eNAMPT monomer and dimer by immunoblotting under non-reducing conditions. eNAMPT monomer was almost absent in serum from individuals without diabetes, but increased markedly in type 2 diabetes. Specifically, in individuals without diabetes, serum eNAMPT was $95.8 \%$ dimer and $4.2 \%$ monomer. However, in type 2 diabetes, serum eNAMPT was $71 \%$ dimer and $29 \%$ monomer, which translated into a mean concentration of $1.83 \mathrm{ng} / \mathrm{ml}$ eNAMPT monomer (Fig. 1c-e). Increasing eNAMPT concentrations did not correlate with serum NMN levels and NMN was not associated with $\mathrm{HbA}_{1 \mathrm{c}}$ (Fig. 1f, g). This suggests a selective pathophysiological role for eNAMPT monomer in type 2 diabetes. Neither eNAMPT nor NMN correlated with BMI, age or serum insulin (ESM Fig. 1).

eNAMPT exerts bimodal effects on beta cell function in mouse and human pancreatic islets Increased $\mathrm{HbA}_{1 \mathrm{c}}$ is indicative of poor glycaemic control and deteriorating beta cell

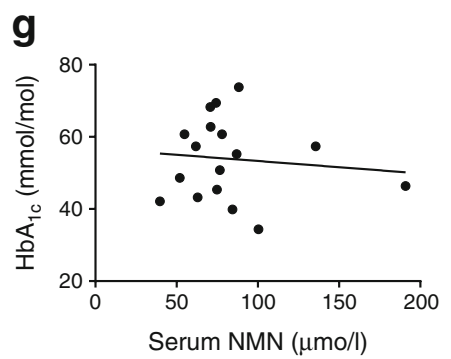

serum from non-diabetic and type 2 diabetic individuals (d) and concentration of eNAMPT monomer and dimer in serum from individuals with type 2 diabetes only (e). In (c-e): $n=4$; data generated from BodyFatS\&H and VaSera trial samples. (f) Serum NMN and (g) serum $\mathrm{NMN}$ vs $\mathrm{HbA}_{1 \mathrm{c}}$ (data generated from VaSera trial only). $n$ values differ for NMN measurements due to limited availability of some samples. Data are expressed as means \pm SEM. $* p<0.05, * * p<0.01$, by one-way ANOVA with Tukey's post hoc test, or Pearson correlation

function. To assess the (patho)physiological effects of eNAMPT on beta cells, we used serum eNAMPT concentrations (as detected in Fig. 1a and [12]) and exposed isolated islets to physiological $(1 \mathrm{ng} / \mathrm{ml})$ and pathophysiological $(5 \mathrm{ng} / \mathrm{ml})$ eNAMPT. To account for batch-to-batch differences between commercially available eNAMPT [8], we generated recombinant wild-type eNAMPT (eNAMPT-WT). To specifically examine eNAMPT monomer, we mutated $\mathrm{Ser}^{199 / 200}$ (key residues in the NAMPT binding interface $[6,20]$ ) to aspartic acid. This generated a $52 \mathrm{KDa}$ protein (eNAMPT monomer), which neither dimerised correctly, as demonstrated by size-exclusion chromatography and native MS, nor synthesised cellular NMN and NAD (ESM Fig. 2a-e). Neither eNAMPT-WT nor eNAMPT monomer contained notable endotoxin concentrations (ESM Fig. 2f)

eNAMPT-WT induced a bimodal response; $1 \mathrm{ng} / \mathrm{ml}$ eNAMPT significantly enhanced static glucose-stimulated insulin secretion (GSIS) in mouse and human islets (2448 h; Fig. 2a, b, e, f), and enhanced dynamic GSIS (48 h; 

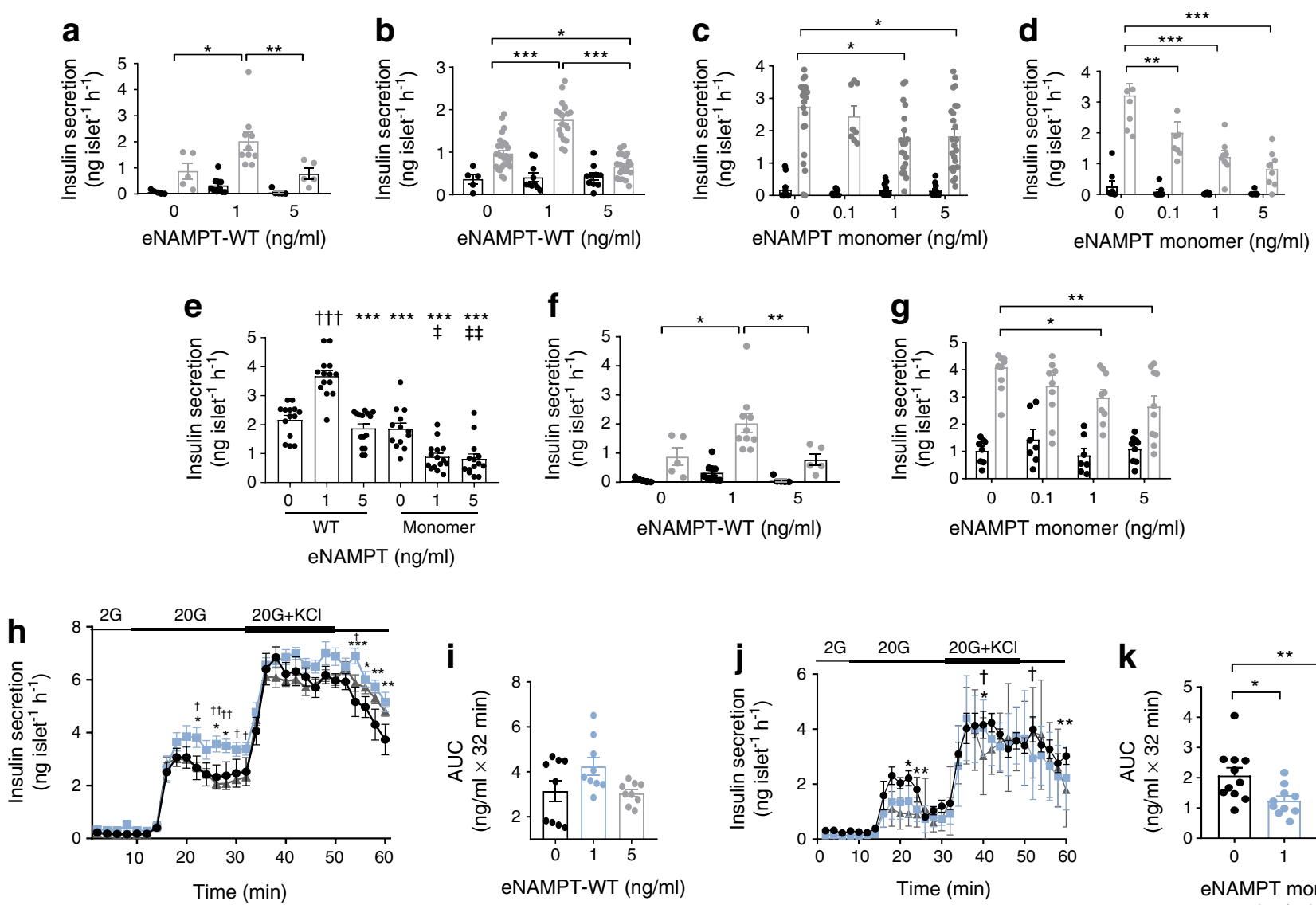
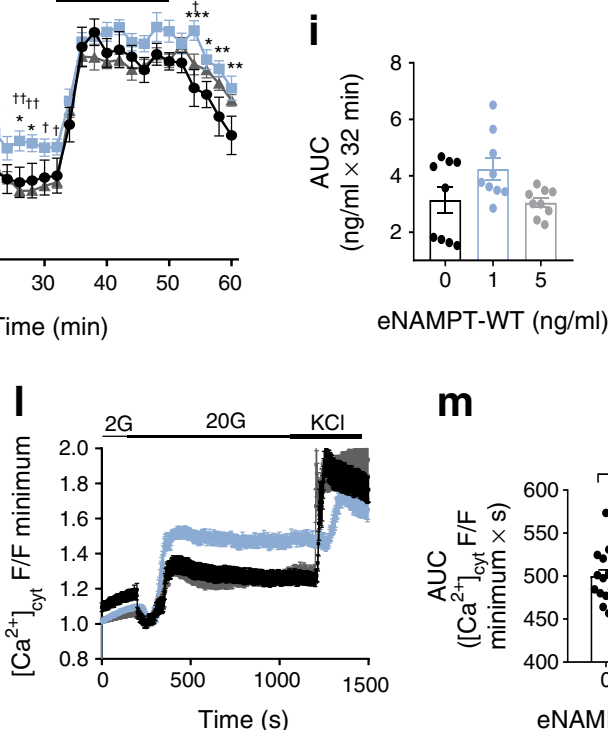

m

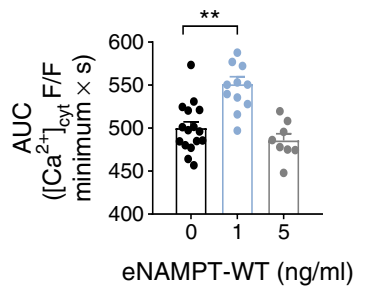

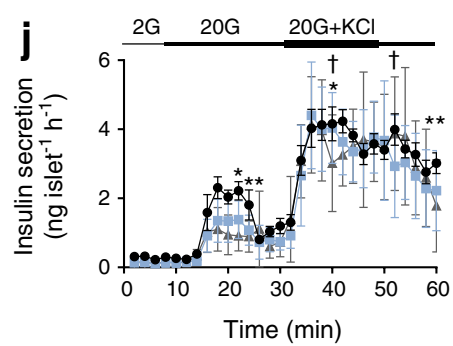

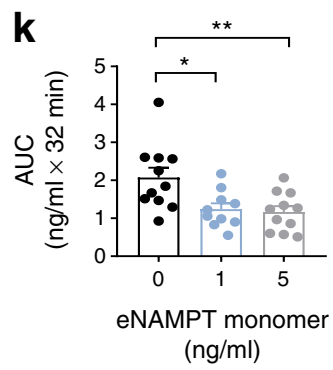

n

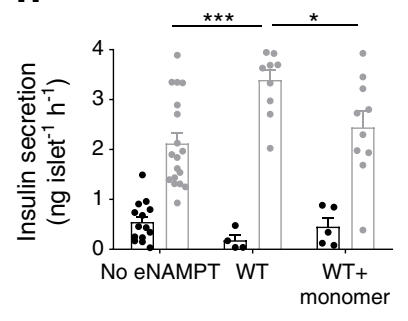

Fig. 2 GSIS has a bimodal response to eNAMPT. (a-d) Static insulin secretion in response to basal $(2 \mathrm{mmol} / \mathrm{l})$ or $20 \mathrm{mmol} / \mathrm{l}$ glucose was assessed in isolated mouse islets incubated with 1 or $5 \mathrm{ng} / \mathrm{ml} \mathrm{eNAMPT-}$ WT for (a) $24 \mathrm{~h}$ and (b) $48 \mathrm{~h}$, or with $0.1,1$ or $5 \mathrm{ng} / \mathrm{ml}$ eNAMPT monomer for (c) $24 \mathrm{~h}$ and (d) $48 \mathrm{~h}$. (e) Static insulin secretion in response to $20 \mathrm{mmol} / \mathrm{l}$ glucose was assessed in isolated mouse islets incubated with 1 or $5 \mathrm{ng} / \mathrm{ml}$ eNAMPT-WT and eNAMPT monomer. (f, g) Static insulin secretion in response to basal $(2 \mathrm{mmol} / \mathrm{l})$ or $20 \mathrm{mmol} / 1$ glucose was assessed in isolated human islets incubated with (f) 1 or $5 \mathrm{ng} / \mathrm{ml}$ eNAMPT-WT or (g) $0.1,1$ or $5 \mathrm{ng} / \mathrm{ml}$ eNAMPT monomer for $48 \mathrm{~h}$. For (a-g): black bars, $2 \mathrm{mmol} / 1$ glucose; grey bars, $20 \mathrm{mmol} / 1$ glucose. $n=5-28$, where an $n$ of 1 equals five islets per incubation tube, repeated 8-10 times. (h-k) Dynamic insulin secretion was assessed in isolated mouse islets incubated with (h, i) 1 or $5 \mathrm{ng} / \mathrm{ml}$ eNAMPT-WT or $(\mathbf{j}, \mathbf{k})$ with 1 or $5 \mathrm{ng} / \mathrm{ml}$ eNAMPT monomer for $48 \mathrm{~h}$ by perifusion with $2 \mathrm{mmol} / \mathrm{l}$ glucose $(2 \mathrm{G})$ or with $20 \mathrm{mmol} / \mathrm{l}$ glucose $(20 \mathrm{G})$ with or without $20 \mathrm{mmol} / 1 \mathrm{KCl} . n=9-12$, where an $n$ of 1 equals one perifusion of 160 islets isolated from 4-6 mice. (l, m) Glucose-stimulated $\left[\mathrm{Ca}^{2+}\right]_{\mathrm{cyt}}$ was

Fig. 2h, i) and intracellular cytosolic calcium levels $\left(\left[\mathrm{Ca}^{2+}\right]_{\text {cyt }}\right)$ (Fig. 21, m; AUC, $p<0.01$ ) in mouse islets. In contrast, neither measured in isolated mouse islets treated with 1 or $5 \mathrm{ng} / \mathrm{ml}$ eNAMPTWT for $48 \mathrm{~h}$ ( $n=9-16$ islets/treatment from three mice). Calcium data are expressed as $\mathrm{F} / \mathrm{F}$ minimum, where $\mathrm{F}$ is fluorescence at any given time point and $\mathrm{F}$ minimum is the minimum fluorescence during the recording. For (h-m): black, $0 \mathrm{ng} / \mathrm{ml}$ eNAMPT; blue, $1 \mathrm{ng} / \mathrm{ml}$ eNAMPT-WT; grey, $5 \mathrm{ng} / \mathrm{ml}$ eNAMPT-WT. (n) Static insulin secretion in response to basal ( $2 \mathrm{mmol} / \mathrm{l})$ or $20 \mathrm{mmol} / \mathrm{l}$ glucose was assessed in isolated mouse islets incubated with $1 \mathrm{ng} / \mathrm{ml}$ eNAMPT-WT $\pm 1 \mathrm{ng} / \mathrm{ml}$ eNAMPT monomer for $48 \mathrm{~h}(n=4-19)$. Black bars, $2 \mathrm{mmol} / 1$ glucose; grey bars, $20 \mathrm{mmol} / 1$ glucose. Data are expressed as means \pm SEM. $* p<0.05$, $* * p<0.01$, $* * * p<0.001$, as indicated. In (e): $* * * p<0.001 \mathrm{vs} 1 \mathrm{ng} / \mathrm{ml}$ eNAMPTWT; ${ }^{\dagger \dagger} p<0.001$ vs $0 \mathrm{ng} / \mathrm{ml}$ eNAMPT-WT; ${ }^{\star} p<0.05,{ }^{\star \star} p<0.01$ vs $0 \mathrm{ng} / \mathrm{ml}$ eNAMPT monomer. In $(\mathbf{h})$ and $(\mathbf{j}): * p<0.05, * * p<0.01$, $* * * p<0.001,0 \mathrm{ng} / \mathrm{ml}$ vs $1 \mathrm{ng} / \mathrm{ml}$ eNAMPT $;{ }^{\dagger} p<0.05,{ }^{\dagger \dagger} p<0.01,1 \mathrm{ng} / \mathrm{ml}$ vs $5 \mathrm{ng} / \mathrm{ml}$ eNAMPT. Data analysed by two-way ANOVA with Tukey's post hoc test $(\mathbf{a}-\mathbf{g}, \mathbf{n})$ or one-way ANOVA with Bonferroni's post hoc test $(\mathbf{h}-\mathbf{m})$

$5 \mathrm{ng} / \mathrm{ml}$ eNAMPT-WT nor eNAMPT monomer $(0.1-5 \mathrm{ng} / \mathrm{ml}$; $48 \mathrm{~h})$ stimulated static or dynamic GSIS or increased 
intracellular calcium in mouse or human islets, with similar or reduced levels of these variables compared with islets not treated with eNAMPT (Fig. 2a-m). A similar bimodal insulin-secretory response was observed following exposure to commercial eNAMPT (Adipogen, Seoul, South Korea; ESM Fig. 3a-c).
We also assessed effects of a combination of eNAMPT-WT and eNAMPT monomer, which is more representative of normal (patho)physiology. eNAMPT-WT $(1 \mathrm{ng} / \mathrm{ml})$ alone induced GSIS as expected; however, when eNAMPT-WT $(1 \mathrm{ng} / \mathrm{ml})$ was added in combination with eNAMPT monomer, the insulin stimulatory effects of eNAMPT-WT were lost (Fig. 2n).
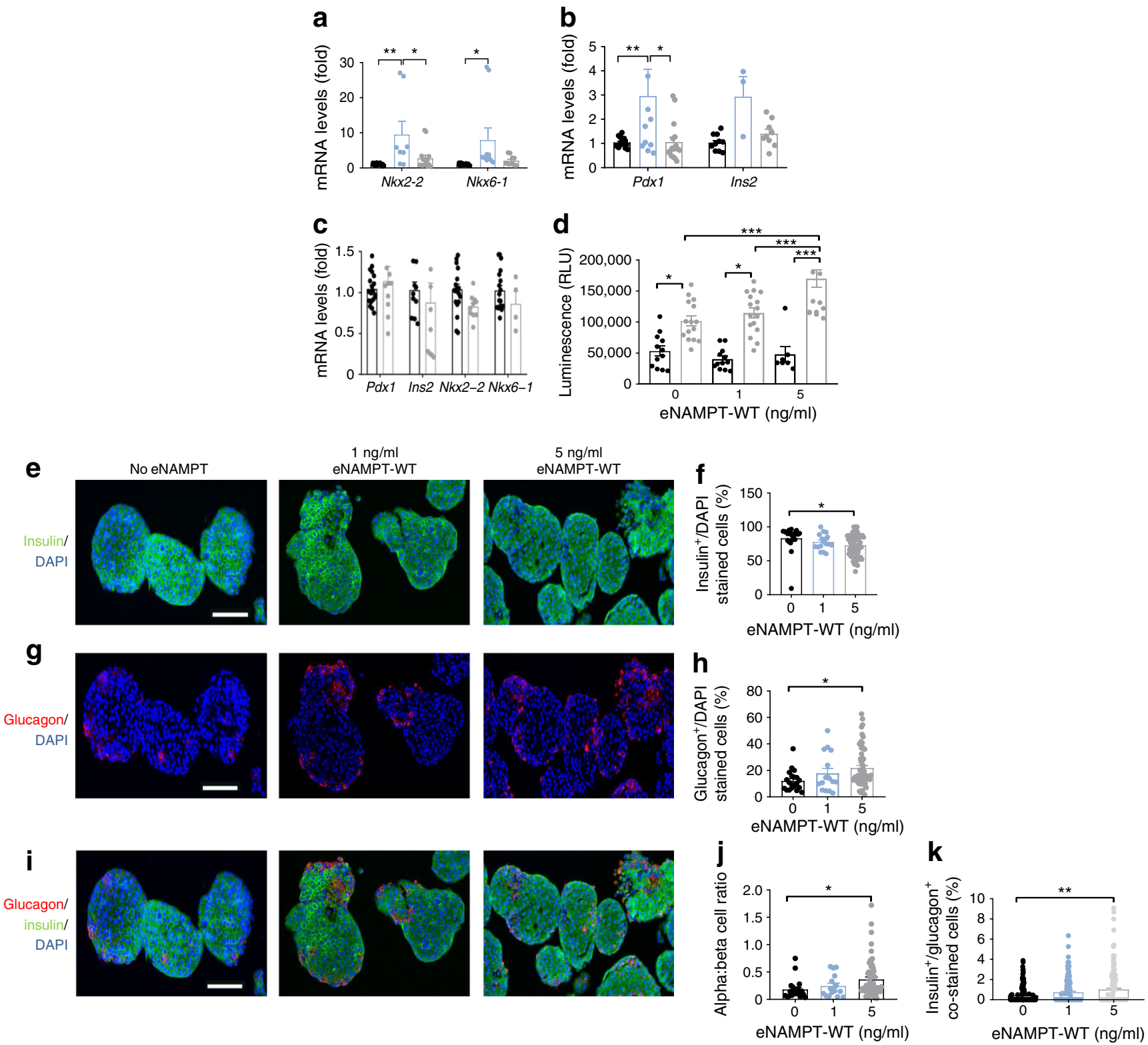

Fig. 3 Pathophysiological eNAMPT mediates reductions in beta cell identity and number. (a-c) Gene expression of $N k x 2-2, N k x 6-1, P d x 1$ and Ins 2 was measured in mouse islets treated with $(\mathbf{a}, \mathbf{b}) 1 \mathrm{ng} / \mathrm{ml}$ eNAMPT-WT (blue bars), $5 \mathrm{ng} / \mathrm{ml}$ eNAMPT-WT (grey bars), or (c) $1 \mathrm{ng} / \mathrm{ml}$ eNAMPT monomer (grey bars) for $48 \mathrm{~h}$. In (a-c), black bars, untreated. (d) Apoptosis (caspase 3/7 activity) was measured in islets treated with eNAMPT-WT with (grey bars) and without (black bars) a cocktail of cytokines (TNF- $\alpha$, IFN $\gamma$ and IL- $1 \beta ; n=7-16$, where an $n$ of 1 equals one well with six size-matched islets); (e-k) Mouse islets were treated with 1 or $5 \mathrm{ng} / \mathrm{ml}$ eNAMPT-WT for $48 \mathrm{~h}$ and assessed by immunofluorescence. (e) Double immunofluorescence images of islets stained for insulin (green) and DAPI (blue) and (f) bar chart showing per cent of insulin ${ }^{+}$DAPI cells. (g) Double immunofluorescence images of islets stained for glucagon (red) and DAPI (blue) and (h) bar chart showing per cent of glucagon ${ }^{+} /$DAPI stained cells. (i) Immunofluorescence images of islets stained for insulin (green), glucagon (red) and DAPI (blue) and (j) bar chart showing per cent DAPI/glucagon ${ }^{+}$:DAPI/insulin ${ }^{+}$cells. (k) Per cent of insulin ${ }^{+} /$glucagon ${ }^{+}$bi-hormonal cells. For $(\mathbf{e}-\mathbf{k}), n=3$, where $n$ of 1 equals 200-300 islets from 1 mouse. Data are expressed as means \pm SEM. $* p<0.05, * * p<0.01, * * * p<0.001$, by two-way ANOVA with Tukey's post hoc test $(\mathbf{a}, \mathbf{b}, \mathbf{d})$ or one-way ANOVA with Bonferroni's post hoc test $(\mathbf{c}, \mathbf{f}, \mathbf{h}, \mathbf{j}, \mathbf{k})$ 
Together this demonstrates that low, physiological levels of eNAMPT enhance beta cell function, but as eNAMPT rises to pathophysiological levels $(\sim 5 \mathrm{ng} / \mathrm{ml})$, beneficial effects are lost and eNAMPT mediates beta cell dysfunction. The effects of high concentrations of eNAMPT-WT are mimicked by nondimerising eNAMPT monomer, consistent with the notion that eNAMPT-WT adopts monomeric structure and function at higher concentrations.

Pathophysiological eNAMPT reduces beta cell number and identity and increases alpha cell number Type 2 diabetes is characterised by reduced beta cell mass, with loss of beta cell identity and increased apoptosis as possible mechanisms. Consistent with the bimodal insulin-secretory response, mRNA levels of islet Ins $2(p>0.05)$ and the essential beta cell identity markers [35] $P d x 1(p<0.01), N k x 2-2(p<0.01)$ and Nkx6-1 $(p<0.05)$ were increased in mouse islets by $1 \mathrm{ng} / \mathrm{ml}$ eNAMPT-WT but not by $5 \mathrm{ng} / \mathrm{ml}$ eNAMPT-WT, nor $1 \mathrm{ng} / \mathrm{ml}$ eNAMPT monomer (48 h; Fig. 3a-c), as compared with untreated islets. Treatment with $5 \mathrm{ng} / \mathrm{ml}$ eNAMPT-WT also enhanced cytokine-mediated islet apoptosis, (caspase 3/7 activity) ( $p<0.001$ vs no eNAMPT; Fig. $3 \mathrm{~d})$, as well as significantly reducing insulin ${ }^{+}$cells $(p<0.05)$ and increasing glucagon $^{+}$cells $(p<0.05)$ and non-significantly increasing somatostatin $^{+}$cells, denoting decreased beta cell and increased alpha and delta cell number, respectively (Fig. 3e-k; ESM Fig. 4).

eNAMPT impairs beta cell function via proinflammatory mechanisms Proinflammatory effects of eNAMPT are reported, although, to date, not in type 2 diabetes. eNAMPT-WT at $5 \mathrm{ng} / \mathrm{ml}(48 \mathrm{~h})$, but not at $1 \mathrm{ng} / \mathrm{ml}$, increased mouse islet $I l l b$ $(p<0.05)$ and $C c l 2(p<0.001)$ gene expression, as compared with untreated islets (Fig. 4a). Similarly, eNAMPT monomer $(1 \mathrm{ng} / \mathrm{ml} ; 48 \mathrm{~h}$ ) increased IL1B/Illb and CCL2/Ccl2 gene expression in mouse and human islets (significant $[p<0.05]$ for Illb only) (Fig. 4b). Inflammatory pathway inhibitors demonstrated that inhibition of STAT3 and P38-MAPK, but not of NF-KB or JNK (inhibition of which still resulted in reduced GSIS; $p>0.05$ for NF-kB and $p<0.05$ for JNK), blocked the inhibitory effects of eNAMPT on GSIS (Fig. 4c).

Therefore, pathophysiological concentrations of eNAMPTWT and eNAMPT monomer induce beta cell dysfunction, in part through promotion of STAT3 and P38-mediated islet inflammation.

\section{Structure-functional changes mediate bimodal effects of} eNAMPT-WT Since the effects of eNAMPT monomer were mimicked by $5 \mathrm{ng} / \mathrm{ml}$, but not $1 \mathrm{ng} / \mathrm{ml}$ eNAMPT-WT, we hypothesised that high concentrations of eNAMPT-WT $(5 \mathrm{ng} / \mathrm{ml})$ would be associated with reduced NADbiosynthetic capacity (compared with $1 \mathrm{ng} / \mathrm{ml}$ eNAMPTWT), indicative of reduced eNAMPT dimer and increased eNAMPT monomer levels.
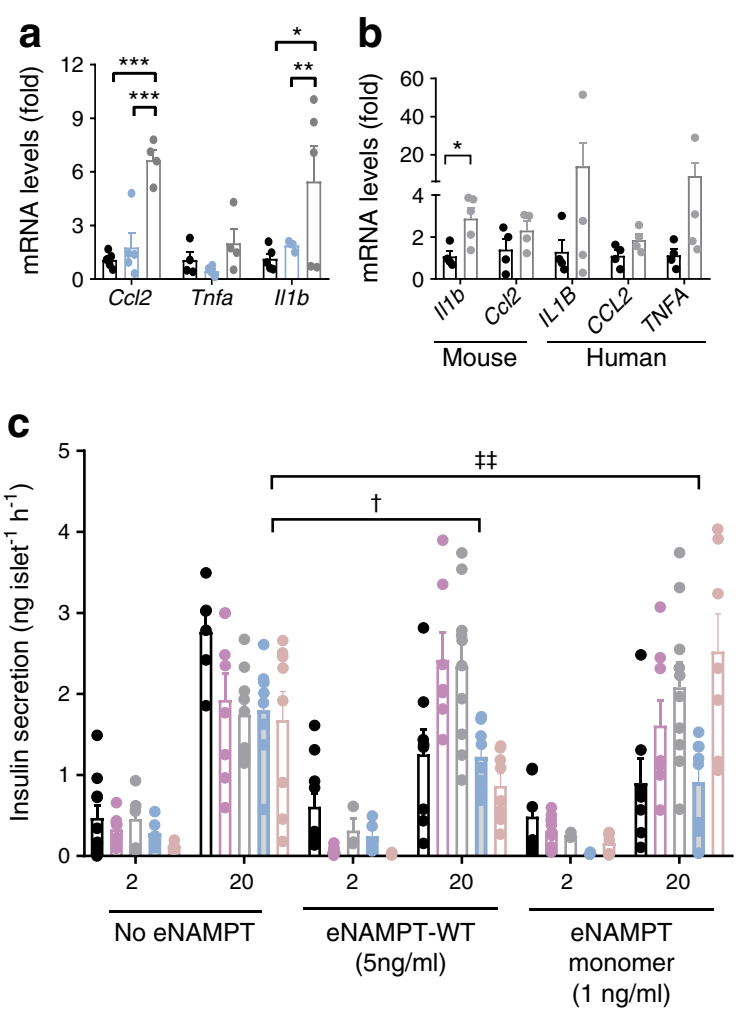

Fig. 4 Monomeric eNAMPT impairs GSIS via proinflammatory mechanisms. (a) Gene expression of $C c l 2, T n f a$ and $I l l b$ in mouse islets after treatment with eNAMPT-WT at $1 \mathrm{ng} / \mathrm{ml}$ (blue bars) or $5 \mathrm{ng} / \mathrm{ml}$ (grey bars) (black bars, untreated); $n=4-5$. (b) Gene expression of Illb/IL1B, Ccl2/ CCL2 and TNFA in mouse and human islets after treatment with $1 \mathrm{ng} / \mathrm{ml}$ eNAMPT monomer (grey bars) (black bars, untreated); $n=4-5$. (c) Mouse islets were treated with $5 \mathrm{ng} / \mathrm{ml}$ eNAMPT-WT or $1 \mathrm{ng} / \mathrm{ml}$ eNAMPT monomer in combination with inhibitors of P38-MAPK (SB203580; $1 \mu \mathrm{mol} / 1$; purple bars), STAT3 (NCS74859; $50 \mu \mathrm{mol} / 1$; grey bars), JNK (SP600125; 50 mol/1; blue bars) or NF-KB (BAY 11-7082; $1 \mu \mathrm{mol} / 1$; brown bars) for $48 \mathrm{~h}$ (no inhibitor, black bars), and insulin secretion was measured after static incubation with $2 \mathrm{mmol} / \mathrm{l}$ or $20 \mathrm{mmol} / 1$ glucose $(n=8-10)$. In $(\mathbf{a}-\mathbf{c})$, an $n$ of 1 equals $150-250$ islets. Data are expressed as means \pm SEM. $* p<0.05, * * p<0.01, * * * p<0.001$, as indicated. In (c): ${ }^{\dagger} p<0.05$ for islets treated with JNK inhibitor and $5 \mathrm{ng} / \mathrm{ml}$ eNAMPT-WT vs islets treated with JNK inhibitor without eNAMPT; ${ }^{\sharp} p<0.01$ for islets treated with JNK inhibitor and $1 \mathrm{ng} / \mathrm{ml}$ eNAMPT monomer vs islets treated with JNK inhibitor without eNAMPT. Data analysed by two-way ANOVA with Sidak's post hoc test

In support of this, treatment of MIN6 cells with $1 \mathrm{ng} / \mathrm{ml}$ eNAMPT-WT $(48 \mathrm{~h})$ increased cellular NMN $(p<0.05)$ and NAD $(p>0.05)$ vs basal levels, by $30 \%$ and $20 \%$, respectively. These changes were mimicked by NMN treatment (100 $\mu \mathrm{mol} / 1$ for $48 \mathrm{~h}$; Fig. $5 \mathrm{a}-\mathrm{d})$. NMN also mimicked the functional effects of $1 \mathrm{ng} / \mathrm{ml}$ eNAMPT-WT, significantly increasing levels of GSIS and Ins2, Nkx2-2 and $P d x I$ mRNA (Fig. 5e, f). In contrast, and similar to the effects of eNAMPT monomer, $5 \mathrm{ng} / \mathrm{ml}$ eNAMPT-WT did not increase cellular NMN or NAD (Fig. 5a-d and ESM Fig. 2d-e). Furthermore, AMP-CP-mediated inhibition of CD73 (a protein involved in cellular NMN uptake) [36-40] inhibited the insulin-secretory effects of $1 \mathrm{ng} / \mathrm{ml}$ eNAMPT-WT $(p<$ 


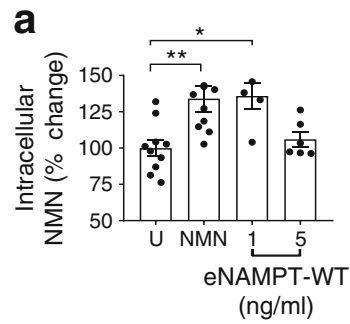

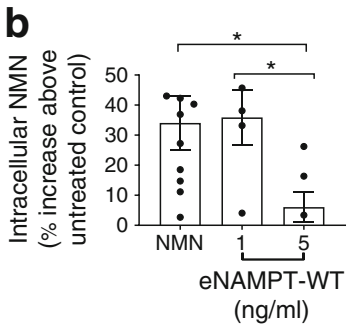

e

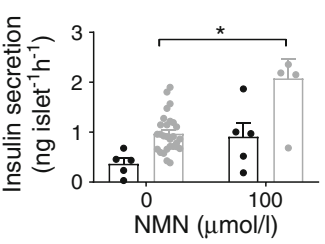

Fig. 5 Structure-functional changes mediate the bimodal effects of eNAMPT-WT. (a-d) MIN6 cells were incubated with either NMN $(100 \mu \mathrm{mol} / \mathrm{l})$ or eNAMPT-WT (1 or $5 \mathrm{ng} / \mathrm{ml})$ for $48 \mathrm{~h}$. (a, b) intracellular $\mathrm{NMN}$ and $(\mathbf{c}, \mathbf{d})$ intracellular NAD. In $(\mathbf{a}-\mathbf{d}), n=5-10$, where $n$ of 1 equals 1 well of a 12-well plate. (e, f) Mouse islets were treated with NMN $(100 \mu \mathrm{mol} / \mathrm{l})$, and (e) static insulin secretion in response to $2 \mathrm{mmol} / \mathrm{l}$ glucose (black bars) or $20 \mathrm{mmol} / 1$ glucose (grey bars) was analysed ( $n=5-28$, where an $n$ of 1 equals five islets per incubation tube, repeated 8-10 times) and (f) gene expression of $P d x 1$, Ins2 and $N k x 2-2$ was measured by quantitative RT-PCR $(n=5-12$, where an $n$ of 1 equals

0.05 ) but had no effects on the inhibitory actions of $5 \mathrm{ng} / \mathrm{ml}$ eNAMPT-WT on GSIS (Fig. $5 \mathrm{~g}$ ). Thus, $1 \mathrm{ng} / \mathrm{ml}$ eNAMPT induces NAD biosynthesis and requires islet NMN uptake to exert its functional effects. In contrast, the effects of $5 \mathrm{ng} / \mathrm{ml}$ eNAMPT were unaffected by inhibition of NMN uptake, suggesting an NAD-independent pathway for these effects.

These data provide evidence that the bimodal effects of eNAMPT-WT are related to loss of NAD-biosynthetic capacity of eNAMPT at higher concentrations.

\section{Discussion}

This study demonstrates that eNAMPT exerts bimodal, concentration- and structure-functional-dependent effects on pancreatic beta cell functional mass, and provides clarification of previous contradictory eNAMPT studies.

Low, physiological levels of eNAMPT (1 ng/ml) enhance beta cell health through NAD-dependent mechanisms. Since islets are continually exposed to low eNAMPT concentrations in healthy non-diabetic individuals, this indicates a role for low eNAMPT concentrations in maintaining beta cell health. Beta cell identity genes were increased at $1 \mathrm{ng} / \mathrm{ml}$ eNAMPT, highlighting the potential importance of physiological levels of eNAMPT in maintaining beta cells in the fully differentiated state. This is consistent with studies showing beta cell dedifferentiation following 3-day culture in the absence of circulating factors, including eNAMPT/NMN [41]. The effects of
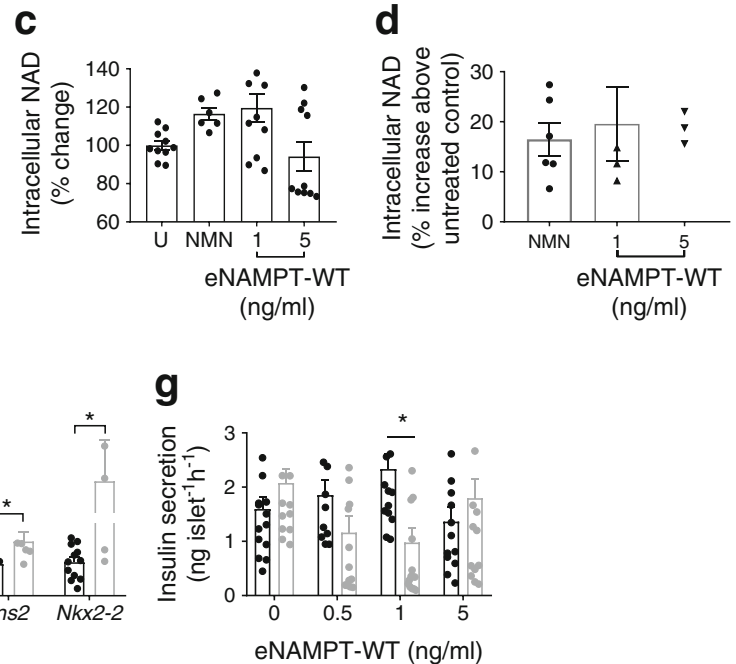

RNA extracted from 150-200 islets). (g) Mouse islets were treated for $48 \mathrm{~h}$ with eNAMPT-WT $(0.5,1$ or $5 \mathrm{ng} / \mathrm{ml})$ in combination with the CD73 inhibitor AMP-CP $(1 \mu \mathrm{mol} / 1)$ and static insulin secretion was measured in response to $20 \mathrm{mmol} / 1$ glucose $(n=17$, where an $n$ of 1 equals five islets per incubation tube, repeated 8-10 times). In (f) and (g): black bars, $0 \mu \mathrm{mol} / 1 \mathrm{NMN}$; grey bars, $100 \mu \mathrm{mol} / 1 \mathrm{NMN}$. Data are expressed as means \pm SEM, $* p<0.05, * * p<0.01$, *** $p<0.001$ vs untreated cells (in (b) and (d), untreated cells are at $0 \%$ ) or as indicated, by one-way ANOVA with Bonferroni's post hoc test (a-d) or two-way ANOVA with Sidak's post hoc test (e-g). U, untreated

$1 \mathrm{ng} / \mathrm{ml}$ eNAMPT are mediated via NAD biosynthesis, suggesting eNAMPT exists in the dimeric form at lower concentrations. This is consistent with our observations in non-diabetic human and mouse serum samples, which show eNAMPT dimer as the predominant structural form of eNAMPT at low physiological concentrations [12]. Whether eNAMPT can exert NAD biosynthesis within the extracellular space remains controversial. Whilst RPMI media contains sufficient nicotinamide to support eNAMPT enzymatic activity, we were unable to detect eNAMPT within spent islet media after eNAMPT incubation, suggesting that at least some eNAMPT dimer is taken up into the islet/beta cell, after which NMN synthesis occurs intracellularly.

Mechanistically, eNAMPT-mediated NAD synthesis may improve beta cell health through activation of NAD-dependent sirtuins or via actions of NAD metabolites cyclic ADP-ribose (cADPR) and nicotinic acid adenine dinucleotide phosphate (NAADP), which reportedly induce intracellular calcium mobilisation [13, 14, 16, 19].

Conversely, as eNAMPT concentrations rise to pathophysiological levels, as in type 2 diabetes, eNAMPT induces islet inflammation, and initiates beta cell dysfunction, beta cell death and reduced beta cell mass and identity. The mechanisms driving reduced beta cell number and identity are unclear. We have demonstrated that high concentrations of eNAMPT enhance beta cell apoptosis, however beta to alpha cell trans-differentiation or beta cell de-differentiation may also play a role, and further studies are required to identify the precise mechanisms. 
eNAMPT exerts beta cell dysfunction through NADindependent mechanisms, suggesting a switch toward monomeric eNAMPT at higher concentrations. This is consistent with observations that the eNAMPT monomer was present at 1$2 \mathrm{ng} / \mathrm{ml}$ in serum from individuals with type 2 diabetes, but almost absent in serum from individuals without diabetes. It is also consistent with our observations that increasing serum eNAMPT did not correlate with increasing serum NMN.

Whilst elevated eNAMPT strongly correlated with increased $\mathrm{HbA}_{1 \mathrm{c}}$, we did not observe notable correlations between eNAMPT and BMI, and only a weak correlation between eNAMPT and serum insulin. We hypothesise that, as glucose rises during glucose intolerance, secretion of eNAMPT dimer increases, which promotes islet compensation. However, as eNAMPT levels continue to rise in response to elevated glucose, eNAMPT dimer begins to break apart into constituent eNAMPT monomers, which then drive beta cell failure. Thus, increases in eNAMPT strongly correlate with increases in blood glucose and $\mathrm{HbA}_{1 \mathrm{c}}$ and do not necessarily precede hyperglycaemia. Precisely why eNAMPT preferentially exists as a monomer at high levels remains unclear but may relate to ligand-induced dimerisation, whereby eNAMPT is stabilised and maintained in dimer form by the presence of an endogenous ligand. We hypothesise that insufficient concentrations of the putative ligand at higher eNAMPT concentrations lead to break up of the dimer into constitutive monomers.

Mechanistically, eNAMPT promoted islet inflammation and beta cell failure through P38-MAPK and STAT3 pathways. Similar eNAMPT effects are reported in macrophages, monocytes and islets of mice fed a high-fat diet (HFD) [7, 9, $12,42]$. Upstream, these effects may be receptor-mediated, with eNAMPT reported to function via Toll-like receptor 4 (TLR4) [43], C-C chemokine receptor type 5 (CCR5) [44], IGF and insulin receptor [8] signalling, although these remain unconfirmed. Separately, the deleterious effects of eNAMPT monomer may also reflect decreased eNAMPT dimermediated NAD synthesis, occurring independently from direct effects of eNAMPT monomer.

Together, our results characterise structure-functional relationships as being of crucial importance to the effects of eNAMPT on beta cell health. Moreover, we demonstrate a novel mechanism of beta cell dysfunction in type 2 diabetes. Strategies to block the actions of the eNAMPT monomer by promoting dimerisation or stabilising eNAMPT in dimer form could represent promising therapeutic approaches for the treatment of diabetes.

Acknowledgements We thank J. I. Miyazaki (Osaka University, Osaka, Japan) for provision and consent to use MIN6 cells. Imaging was conducted in the Nikon Imaging Centre at King's College London (London, UK).

Contribution statement SRS, GCH, PC, RLB, NHFF, KJP, PEB, SB, $\mathrm{DJH}, \mathrm{GGL}$ and $\mathrm{PWC}$ designed and conducted the research, analysed the data and reviewed and approved the final manuscript. A-TM, MPS and SDP designed, conducted and analysed the Body Fat, Surgery and Hormone (BodyFatS\&H) study and reviewed and approved the final manuscript; CEM and JKC designed, conducted and analysed the VaSera study and reviewed and approved the final manuscript. SRS and PWC wrote the paper. PWC is the guarantor of this work.

Open Access This article is distributed under the terms of the Creative Commons Attribution 4.0 International License (http:// creativecommons.org/licenses/by/4.0/), which permits unrestricted use, distribution, and reproduction in any medium, provided you give appropriate credit to the original author(s) and the source, provide a link to the Creative Commons license, and indicate if changes were made.

\section{References}

1. DeFronzo RA, Abdul-Ghani MA (2011) Preservation of beta-cell function: the key to diabetes prevention. J Clin Endocrinol Metab 96(8):2354-2366

2. Imai S (2009) Nicotinamide phosphoribosyltransferase (Nampt): a link between NAD biology, metabolism, and diseases. Curr Pharm Des 15(1):20-28

3. Imai S, Yoshino J (2013) The importance of NAMPT/NAD/SIRT1 in the systemic regulation of metabolism and ageing. Diabetes Obes Metab 15(Suppl 3):26-33

4. Samal B, Sun Y, Stearns G, Xie C, Suggs S, McNiece I (1994) Cloning and characterization of the cDNA encoding a novel human pre-B cell colony-enhancing factor. Mol Cell Biol 14(2):14311437

5. Rongvaux A, Shea RJ, Mulks MH et al (2002) Pre-B cell colonyenhancing factor, whose expression is up-regulated in activated lymphocytes, is a nicotinamide phosphoribosyltransferase, a cytosolic enzyme involved in NAD biosynthesis. Eur J Immunol 32(11):3225-3234

6. Revollo JR, Korner A, Mills KF et al (2007) Nampt/PBEF/visfatin regulates insulin secretion in beta cells as a systemic NAD biosynthetic enzyme. Cell Metab 6(5):363-375

7. Li Y, Zhang Y, Dorweiler B et al (2008) Extracellular Nampt promotes macrophage survival via a nonenzymatic interleukin-6/ STAT3 signaling mechanism. J Biol Chem 283(50):34833-34843

8. Fukuhara A, Matsuda M, Nishizawa M et al (2005) Visfatin: a protein secreted by visceral fat that mimics the effects of insulin. Science. 307(5708):426-430

9. Moschen AR, Kaser A, Enrich B et al (2007) Visfatin, an adipocytokine with proinflammatory and immunomodulating properties. J Immunol 178(3):1748-1758

10. Lopez-Bermejo A, Chico-Julia B, Fernandez-Balsells $\mathrm{M}$ et al (2006) Serum visfatin increases with progressive beta-cell deterioration. Diabetes. 55(10):2871-2875

11. Chang YH, Chang DM, Lin KC, Shin SJ, Lee YJ (2011) Visfatin in overweight/obesity, type 2 diabetes mellitus, insulin resistance, metabolic syndrome and cardiovascular diseases: a meta-analysis and systemic review. Diabetes Metab Res Rev 27(6):515-527

12. Kieswich J, Sayers SR, Silvestre MF, Harwood SM, Yaqoob MM, Caton PW (2016) Monomeric eNAMPT in the development of experimental diabetes in mice: a potential target for type 2 diabetes treatment. Diabetologia. 59(11):2477-2486

13. Caton PW, Kieswich J, Yaqoob MM, Holness MJ, Sugden MC (2011) Nicotinamide mononucleotide protects against pro- 
inflammatory cytokine-mediated impairment of mouse islet function. Diabetologia. 54(12):3083-3092

14. Caton PW, Richardson SJ, Kieswich J et al (2013) Sirtuin 3 regulates mouse pancreatic beta cell function and is suppressed in pancreatic islets isolated from human type 2 diabetic patients. Diabetologia. 56(5):1068-1077

15. Yoon MJ, Yoshida M, Johnson S et al (2015) SIRT1-mediated eNAMPT secretion from adipose tissue regulates hypothalamic $\mathrm{NAD}^{+}$and function in mice. Cell Metab 21(5):706-717

16. Yoshino J, Mills KF, Yoon MJ, Imai S (2011) Nicotinamide mononucleotide, a key $\mathrm{NAD}^{+}$intermediate, treats the pathophysiology of diet- and age-induced diabetes in mice. Cell Metab 14(4):528-536

17. Kim DS, Kang S, Moon NR, Park S (2014) Central visfatin potentiates glucose-stimulated insulin secretion and beta-cell mass without increasing serum visfatin levels in diabetic rats. Cytokine. 65(2):159-166

18. Spinnler R, Gorski T, Stolz K et al (2013) The adipocytokine Nampt and its product NMN have no effect on beta-cell survival but potentiate glucose stimulated insulin secretion. PLoS One 8(1): e54106

19. Ramsey KM, Mills KF, Satoh A, Imai S (2008) Age-associated loss of Sirt1-mediated enhancement of glucose-stimulated insulin secretion in beta cell-specific Sirt1-overexpressing (BESTO) mice. Aging Cell 7(1):78-88

20. Wang T, Zhang X, Bheda P, Revollo JR, Imai S, Wolberger C (2006) Structure of Nampt/PBEF/visfatin, a mammalian NAD ${ }^{+}$ biosynthetic enzyme. Nat Struct Mol Biol 13(7):661-662

21. Xiang RL, Mei M, Su YC, Li L, Wang JY, Wu LL (2015) Visfatin protects rat pancreatic $\beta$-cells against IFN- $\gamma$-induced apoptosis through AMPK and ERK1/2 signaling pathways. Biomed Environ Sci 28(3):169-177

22. Brown JE, Onyango DJ, Ramanjaneya M et al (2010) Visfatin regulates insulin secretion, insulin receptor signalling and mRNA expression of diabetes-related genes in mouse pancreatic beta-cells. J Mol Endocrinol 44(3):171-178

23. Mills CE, Govoni V, Faconti L et al (2017) Reducing arterial stiffness independently of blood pressure: the VaSera trial. J Am Coll Cardiol 70(13):1683-1684

24. Faconti L, Mills CE, Govoni V et al (2019) Cardiac effects of 6 months' dietary nitrate and spironolactone in patients with hypertension and with/at risk of type 2 diabetes, in the factorial design, double-blind, randomized controlled VaSera trial. Br J Clin Pharmacol 85(1):169-180

25. Huang GC, Zhao M, Jones P et al (2004) The development of new density gradient media for purifying human islets and islet-quality assessments. Transplantation. 77(1):143-145

26. Jones PM, Salmon DM, Howell SL (1988) Protein phosphorylation in electrically permeabilized islets of Langerhans. Effects of Ca2+, cyclic AMP, a phorbol ester and noradrenaline. Biochem J 254(2): 397-403

27. Ishihara H, Asano T, Tsukuda K et al (1993) Pancreatic beta cell line MIN6 exhibits characteristics of glucose metabolism and glucose-stimulated insulin secretion similar to those of normal islets. Diabetologia. 36(11):1139-1145

28. Sakurada M, Kanatsuka A, Saitoh T et al (1993) Relation between glucose-stimulated insulin secretion and intracellular calcium accumulation studied with a superfusion system of a glucose-responsive pancreatic beta-cell line MIN6. Endocrinology. 132(6):2659-2665
29. Formentini L, Moroni F, Chiarugi A (2009) Detection and pharmacological modulation of nicotinamide mononucleotide $(\mathrm{NMN})$ in vitro and in vivo. Biochem Pharmacol 77(10):1612-1620

30. Zhang RY, Qin Y, Lv XQ et al (2011) A fluorometric assay for highthroughput screening targeting nicotinamide phosphoribosyltransferase. Anal Biochem 412(1):18-25

31. Caton PW, Nayuni NK, Kieswich J, Khan NQ, Yaqoob MM, Corder R (2010) Metformin suppresses hepatic gluconeogenesis through induction of SIRT1 and GCN5. J Endocrinol 205(1):97106

32. Retnakaran R, Youn BS, Liu Y et al (2008) Correlation of circulating full-length visfatin (PBEF/NAMPT) with metabolic parameters in subjects with and without diabetes: a cross-sectional study. Clin Endocrinol 69(6):885-893

33. Flehmig G, Scholz M, Kloting N et al (2014) Identification of adipokine clusters related to parameters of fat mass, insulin sensitivity and inflammation. PLoS One 9(6):e99785

34. Esteghamati A, Alamdari A, Zandieh A et al (2011) Serum visfatin is associated with type 2 diabetes mellitus independent of insulin resistance and obesity. Diabetes Res Clin Pract 91(2):154-158

35. Marchetti P, Bugliani M, De Tata V, Suleiman M, Marselli L (2017) Pancreatic beta cell identity in humans and the role of type 2 diabetes. Front Cell Dev Biol 5:55

36. Fletcher RS, Ratajczak J, Doig CL et al (2017) Nicotinamide riboside kinases display redundancy in mediating nicotinamide mononucleotide and nicotinamide riboside metabolism in skeletal muscle cells. Mol Metab 6(8):819-832

37. Ratajczak J, Joffraud M, Trammell SA et al (2016) NRK1 controls nicotinamide mononucleotide and nicotinamide riboside metabolism in mammalian cells. Nat Commun 7:13103

38. Nikiforov A, Dolle C, Niere M, Ziegler M (2011) Pathways and subcellular compartmentation of NAD biosynthesis in human cells: from entry of extracellular precursors to mitochondrial NAD generation. J Biol Chem 286(24):21767-21778

39. Garavaglia S, Bruzzone S, Cassani C et al (2012) The highresolution crystal structure of periplasmic Haemophilus influenzae NAD nucleotidase reveals a novel enzymatic function of human CD73 related to NAD metabolism. Biochem J 441(1):131-141

40. Yegutkin GG, Marttila-Ichihara F, Karikoski M et al (2011) Altered purinergic signaling in CD73-deficient mice inhibits tumor progression. Eur J Immunol 41(5):1231-1241

41. Negi S, Jetha A, Aikin R, Hasilo C, Sladek R, Paraskevas S (2012) Analysis of beta-cell gene expression reveals inflammatory signaling and evidence of dedifferentiation following human islet isolation and culture. PLoS One 7(1):e30415

42. Matsuda T, Omori K, Vuong T et al (2005) Inhibition of p38 pathway suppresses human islet production of pro-inflammatory cytokines and improves islet graft function. Am J Transplant 5(3):484493

43. Camp SM, Ceco E, Evenoski CL et al (2015) Unique Toll-like receptor 4 activation by NAMPT/PBEF induces NFKB signaling and inflammatory lung injury. Sci Rep 5:13135

44. Van den Bergh R, Morin S, Sass HJ et al (2012) Monocytes contribute to differential immune pressure on R5 versus X4 HIV through the adipocytokine visfatin/NAMPT. PLoS One 7(4):e35074

Publisher's note Springer Nature remains neutral with regard to jurisdictional claims in published maps and institutional affiliations. 